\title{
Why Do Individuals Select into Congruent vs. Discrep- ant Drinking Partnerships?
}

\author{
Jacquelyn D Wiersma-Mosley ${ }^{1 *}$, Judith L Fischer ${ }^{2}$ and Benjamin Smith ${ }^{3}$ \\ ${ }^{1}$ School of Human Environmental Sciences, University of Arkansas, Fayetteville, Arkansas, USA \\ ${ }^{2}$ Department of Human Development and Family Studies, Texas Tech University, Lubbock, Texas, USA \\ ${ }^{3}$ School of Human Environmental Sciences, University of Arkansas, Fayetteville, Arkansas, USA
}

*Corresponding author: Jacquelyn D Wiersma-Mosley, School of Human Environmental Sciences, University of Arkansas, 118 HOEC, Fayetteville, Arkansas 72701, USA, Tel: +1 4795754688; Fax: +1 4795757171; E-mail: jwiersma@uark.edu

Citation: Wiersma-Mosley JD, Fischer JL, Smith B (2016) Why Do Individuals Select into Congruent vs. Discrepant Drinking Partnerships? Gavin J Addict Res Ther 2016: 1-10.

Received: 31 March, 2016; Accepted: 23 April, 2016; Published: 07 May, 2016

\begin{abstract}
The present study examined risk factors that may explain why individuals select into discrepant vs. congruent drinking partnerships during young adulthood. The drinking partnership literature finds that there are a host of consequences for couples who drink discrepantly, where one partner consumes more alcohol and drinks more frequently than the other partner, as compared to those who drink congruently. Data come from the Add Health with 1433 young adults and their partners. Drinking partnerships were based on alcohol frequency, quantity, binge drinking, and getting drunk. Four clusters included Congruent Light and Infrequent, Discrepant Male Heavy/Frequent, Discrepant Female Heavy/Frequent, and Congruent Heavy/Frequent, which resulted in 1,188 congruent couples and 245 discrepant couples. Individuals already risky in their behaviors, such as adolescent delinquency and befriending high drinking peers, were more likely to select into discrepant drinking partnerships.
\end{abstract}

\section{Keywords}

Adolescence; Drinking partnerships; Risk factors; Young adulthood

\section{Why Do Individuals Select into Congruent vs. Discrepant Drinking Partnerships?}

The purpose of this study is to examine the risk factors that explain why individuals select into risky drinking partnerships during young adulthood. In selection processes, people seek out certain partners and maintain relationships with those who have goals, values, and behaviors that are similar to their own [1], including drinking [2]. However, there is a lack of understanding of how "dissimilarities" matter in relationships, thus research that moves to a greater focus on the processes by which similar and different partners negotiate their drinking and their relationship is warranted. Most people find similarity rewarding, but some people may find differences rewarding [3]. The nature of difference and the reward value for being different may depend on the individual. For example, why do some couples choose a partner who drinks more than themselves, i.e., discrepantly? With little theory on attraction to dissimilar others, this study explores possible covariates in a large, national dataset on young adult romantic couples, and considers selection effects as part of a larger endeavor to better understand such associations with congruent and discrepant drinking partnerships. Thus, this study aims not to predict the level of drinking; rather, it aims to predict the level of drinking discrepancy based on the drinking partnership literature on discrepancy and congruency. After reviewing conceptualizations of drinking partnerships and selection, this study discusses important young adult risk factors (intrapersonal and interpersonal) that may affect an individuals' choosing of a certain drinking partnership. Gender is believed to form an important interpersonal context for couple drinking; indeed typologies of drinking partnerships in emerging and young adult are gendered $[2,4]$. 
Citation: Wiersma-Mosley JD, Fischer JL, Smith B (2016) Why Do Individuals Select into Congruent vs. Discrepant Drinking Partnerships? Gavin J Addict Res Ther 2016: 1-10.

\section{Drinking Partnerships and Consequences}

Roberts and Leonard [5] and Wiersma and colleagues $[4,6,7]$ have been researching drinking partnerships in dating, cohabiting and married couples and how these effect romantic relationships and individual behaviors. They have identified both congruent and discrepant drinking groups based on the typical quantity and frequency of alcohol intake, and similarities and differences between partners' drinking levels. Heavier drinking partnerships, whether congruent or discrepant, contribute to the negative effects of drinking relationships in young adults. When couples consume large levels of alcohol, they have a higher risk of experiencing negative consequences such as alcohol-related problems and abuse [6,8-10] and relationship problems [4-7,11]. But more specifically, one common characteristic in the drinking partnership literature is that there are a host of consequences for couples who drink discrepantly, where one partner consumes more alcohol and drinks more frequently than the other partner, as compared to those who drink congruently [12]. For example, couples who drink discrepantly in their relationships report lower satisfaction, commitment $[5,6,13,14]$, relationship dissolution [15], and even relationship violence $[7,16]$. Given that relationships and alcohol-use behaviors are formative life choices, and potentially risky ones, understanding these experiences and why certain partnerships are selected is important.

\section{Selection framework}

Selection effects generally refer to the influence of certain individual characteristics that steer young adults toward particular experiences or people [17-19]. Assortative pairing describes the influences and meaning behind pairing up with similar partners. Thus, relationships do not develop at random, but partners choose one another based on similar characteristics that may include drinking patterns and similar background characteristics, such as age, ethnicity, and education. In part, young adults develop relationships based on similarity, where they are attracted to and match up with others who are similar. Under assortative pairing, there is a similarity between romantic partners that preexists before the relationship and becomes a factor in the formation of the romantic relationship [2].

Affiliating with similar others may be because similarity induces liking or attraction to another individual [20]. An individual who shares similar attitudes, interests, and circumstances with a partner associates these with a positive meaning and may be rewarded by feeling connected or attracted to the romantic partner. As Emirbayer and Goodwin [21] suggested, individuals have an important role in creating the very networks (e.g., drinking partnerships) that exert a significant influence on them. There are benefits to selecting similar others such as: (a) increased feelings of being understood; (b) a mutually satisfying partnership with more satisfaction, intimacy, and relationship longevity than seen among dissimilar individuals [22,23] (c) less conflict and more love, positivity, commitment [24] and (d) more frequent mutual leisure activities [25]. As Klohnen and Luo [26] noted, similarity predicts initial attraction, and perceived similarity is related to increased feelings of being understood (i.e., positive reinforcement). Based on the idea of selection, individuals who consume alcohol may be more likely to choose partners who also consume alcohol because this is a common interest or behavior that couples share together. Thus, pairing up with a drinking partner can be rewarding for each member of the couple.

However, not all couples choose similar romantic partners. Why do discrepant pairings come about when existing work portrays similarity as positive, while differences are often depicted as negative? For example, individuals are less satisfied when they differ on certain traits rather than when they match [27]. Additionally, when individuals have differing perceptions of their relationship courtship patterns, there is less longevity [28]. However, Byrne and Lamberth [29] suggested that differences are not damaging to a relationship, rather complementarity should be viewed as positive. Aron and colleagues [30-31] developed self-expansion theory to describe why individuals are attracted to partners different from themselves: those differences are perceived to offer maximum possibilities or rewards for expanding the self. A potential partner with different interests offers new experiences and possibilities, which should provide new and rewarding feelings. Although most people find similarity rewarding, some people may find differences rewarding [3]. The nature of difference and the reward value for being different may depend on the individual. For some, attraction may be in pursuit of the dissimilar drinking partner because a similar partner would seem to offer fewer possibilities for new experiences. In this view, drinking dissimilarity could be one arena between partners that provides even greater reward value for the expanding self. Although there are fewer of these types of couples $[4-7,12]$, they may represent an extremely interesting and risky group in terms of alcohol behaviors. The focus for this study is to better understand the basis for discrepant and congruent drinking partnerships through the use of a nationally representative and longitudinal design.

\section{Risk factors}

Behaviors that compromise health are often placed within a framework of deviance or risk taking. According to the risk factor typology of Hawkins et al., [32] and Petraitis et al., [33], the following factors may predict alcohol use in young adults, and subsequently drinking partnerships within romantic relationships: intrapersonal variables such as personality attributes (low self-esteem, high novelty seeking or sensation seeking), psychopathology (depression), delinquency, adolescent alcohol use; and interpersonal variables such as parental and peer alcohol use. These variables may help in explaining why non-drinking or lower drinking individuals select higher drinking romantic partners. 
Citation: Wiersma-Mosley JD, Fischer JL, Smith B (2016) Why Do Individuals Select into Congruent vs. Discrepant Drinking Partnerships? Gavin J Addict Res Ther 2016: 1-10.

\section{Intrapersonal factors}

Delinquency and adolescent alcohol use: It has been repeatedly demonstrated that alcohol use and delinquency during adolescence and young adulthood are associated [34]. The experiences with alcohol and delinquency that occur earlier in life are assumed to lead to future riskier values, attitudes, and behaviors [35]. For example, as adolescents develop into young adults, a risky orientation may manifest itself in new behaviors, such as selecting into risky and discrepant drinking partnerships. Delinquent and drinking behaviors may lead to poor decision making with regards to romantic partners. Consequently, the field of potential partners shrinks to those also involved in such acts. Sterk [36] found that drug-addicted women felt increasingly uncomfortable around individuals who did not share their values and, as a result, had a smaller pool of available partners. As the networks shrink individuals engaged in delinquent and risky drinking behaviors may have a smaller pool for selecting romantic partners. Individuals may have no choice but to select partners from among those with delinquent behaviors who drink differently, namely higher, than themselves. With respect to the higher drinking individual selecting a lower drinking partner, they may be seeking another who can expand their possibilities beyond the risky path they travel. Finding such a person may be a challenge.

Depression and self-esteem: Depression and low self-esteem may also be important risk factors when understanding selection into risky and discrepant drinking partnerships. Heavy drinking, for example, is likely among people who experience stress and drink for coping motives [37]. Furthermore, studies have found a strong association between depression and alcohol use for women [38,39], with evidence suggesting that, in women, depression tends to come before alcohol problems [40,41]. Perhaps, individuals, and specifically women, who are depressed but lower users of alcohol may consequently choose a discrepantly drinking partner en route with partner approval to drink in order to cope with depression. Depression may involve paying attention to one's moods and concerns, and a few studies have found that it is positively correlated with avoidance coping, the tendency to avoid one's mood through reckless behaviors, such as excessive drinking of alcohol [42-45]. Baumeister [46] argued that excessive alcohol consumption can be an attempt to escape from the self. Thus, a more depressed heavier drinking actor may choose a lower drinking partner as a way to escape from the self.

Along with depression, lower self-esteem has been found to be associated with young adult alcohol use [47]. Low self-esteem ranks among the strongest predictors of emotional and behavioral problems. Compared to individuals with high self-esteem, those with low self-esteem tend to be more anxious, depressed, lonely, jealous, shy, and generally unhappy [48]. Furthermore, they are more inclined to behave in ways that pose a danger to themselves or others: low self-esteem is associated with the abuse of alcohol and other drugs, and membership in deviant groups [49-51]. It seems likely that individuals with low drinking but also low self-esteem may choose or be chosen by a partner heavier in alcohol use. Thus, perhaps, individuals with low self-esteem may think they could not do better. The low self-esteem and heavier drinking partner may derive reassurance from a lower drinking partner's willingness to be together in spite of drinking, leading them to select a partner who is very different from them, especially in terms of drinking alcohol.

Sensation seeking: One important personality characteristic that may help explain young adults selection into risky and discrepant drinking partnerships is sensation seeking. Sensation seeking is defined as a strong need for varied, novel, and stimulated experiences and willingness to take risks for the sake of such experiences [52]. These traits have been identified as predictors of alcohol involvement [53-55]. Sensation seeking represents a kind of exploration for many young adults, as it involves the pursuit of novel and intense experiences [55,56]. Furthermore, one longitudinal study found that sensation seeking increased from age 15 to 24 [57], while other studies concluding that sensation seeking increases with age, especially during young adulthood [58-61]. Alcohol often increases positive arousal [62], and those who are motivated to consume alcohol may achieve an optimal level of stimulation [54]. Higher levels of sensation seeking could potentially explain why individuals select into discrepant drinking partnerships as heavier discrepant drinking partners provide this type of stimulation and risky experience.

\section{Interpersonal factors}

Parental and peer drinking: Given the developmental trajectory of drinking for young adults, it seems likely that alcohol behavior would generalize to successive relationships, from relationships with parents, to relationships with peers, and to relationships with romantic partners. Parental and peer drinking may serve as predictors of drinking within romantic relationships because parents and peers often play an active role in introducing adolescents to alcohol [63]. An individual's first experience with alcohol is likely to be within the context of the family or peer group where they serve as role models for how to drink, what occasions are appropriate to drink, and for what reasons alcohol is consumed [64,65]. Researchers speculate that when adolescents are in drinking situations or given opportunities to drink, they may follow patterns of alcohol use they recall from their parents and their peer groups [66]. Parents and peers may also influence individuals' alcohol use directly (e.g., through modeling alcohol use) and indirectly (e.g., through individuals' perceptions about their parents' and peers' drinking; [67]). One study found that the more alcohol parents' reported drinking, the greater the quantity of alcohol their adolescent sons and daughters consumed [68]. 
Citation: Wiersma-Mosley JD, Fischer JL, Smith B (2016) Why Do Individuals Select into Congruent vs. Discrepant Drinking Partnerships? Gavin J Addict Res Ther 2016: 1-10.

Peers and parental influences have been examined in various longitudinal studies of adolescents. One study measured progression to heavy drinking and found that friends' drinking was the most significant predictor of adolescents' alcohol use [69], whereas another study concluded that there were substantial environmental and genetic factors that contributed to the relationship between adolescents' own alcohol use and that of their friends, based on parental drinking behaviors [70]. Thus, both the behaviors of parents and peers are relevant contributors to the development of young adult drinking partnerships and could potentially explain why individuals choose drinking partners that are risky (i.e., discrepant).

\section{Gender}

In addition to identifying selection effects in drinking partnerships, it is also important to examine how gender may play a role in drinking partnerships. Men and women may select into drinking partnerships differently. Within romantic relationships, researchers have often emphasized that women have a stronger relational orientation [71] and learn to center much time and energy on their romantic endeavors. Thus, selection into discrepant drinking partnerships may be more powerful and more important for women, whose involvement in drinking may be more determined by and contingent upon the behavior of their male partners [72], and women's use of alcohol may be motivated by a desire to maintain the relationship [73,74]. Women may adapt their drinking to that of their male partner in order to enhance the relationship. A number of studies have shown that women's drinking is strongly associated with their perceptions of their male partners' drinking [75,76]. However, there has been some research that has found the opposite effect - where wives' drinking actually influenced husbands' drinking [76,77]. Men in young adult romantic relationships were more influenced by their female partners' drinking from adolescence to young adulthood [2]. With mixed results in this area, further examination is needed. This study analyses the processes separately for men and women.

\section{The current study}

The present study is designed to examine the risk factors that are associated with selection into young adult discrepant vs. congruent drinking partnerships. Based on previous drinking partnership and risky behaviors literature, the current study hypothesizes that individuals who select into discrepant drinking partnerships will report more intra- and interpersonal problems compared to those who select into congruent drinking partnerships. Lastly, gender will be explored as it relates to selection into drinking partnerships.

\section{Method}

Data were drawn from The National Longitudinal Study of Adolescent to Adult Health (Add Health), which is a school-based, longitudinal study in the US that begun in 1995 of health-related behaviors of adolescents and their outcomes in young adulthood [78]. Wave 1 In-Home ( $\mathrm{N}=20,745$ participants, as well as their parents, primarily mothers) was collected between April and December 1995. Between April and August of 1996, approximately 1 year after the collection of the Wave I In-Home data set, participants were assessed for a second time $(\mathrm{N}=14,738)$ in Wave II In-Home. Wave III In-Home was collected approximately six years later from August 2001 to April 2002, when original participants were young adults (aged 18-26 years). The Wave III data set contains 15,197 respondents and was designed to collect data on attitudes, behaviors, and outcomes in late adolescence and young adulthood, particularly focusing on romantic relationships. This study primarily used the Romantic Pairs subsample of the Wave III dataset that includes 1,507 paired romantic partners from approximately one-third married, one-third cohabitating, and one-third dating partners. Relationships reported by the Wave III respondents were eligible for inclusion in the romantic pairs subsample if they met three criteria: opposite sex relationships, a current relationship, and partner is 18 or older.

This study used In-Home data from Wave I, Wave II, Wave III, and the Romantic Pairs subsample of the Wave dataset. Couples were only retained if they were young adults and between the ages of 18 and 30 (74 couples had at least one partner over the age of 30) resulting in 1433 young adult couples. From our sample, 407 couples were dating (28\%), 536 were cohabitating (37\%), and 490 were married (34\%). In the description that follows, participants are those people for whom there were data collected at Waves I (with parent data), II, and III. Partners are those for whom there was only Wave III data.

\section{Measures}

Demographic controls: Controls in place for background demographic characteristics included self-report responses for age, ethnicity (\% White), highest education (highest year of regular school completed, ranging from $6^{\text {th }}$ grade to 5 or more years of graduate school; i.e., $12=12^{\text {th }}$ grade), and enrollment in a 2 or 4 year college. Table 1 displays all the variable demographics and measures, including means, standard deviations, and alphas.

\section{Intrapersonal factors}

Delinquency was assessed with items that constituted general nonviolent delinquent acts during adolescence (averaged across Waves I and II) and young adulthood (Wave III). In the adolescent years, 11 items included painting graffiti or signs on someone else's property or in a public place; deliberately damaging property that didn't belong to them; lying to parents/guardians about where they had been or whom they were with; taking something from a store without paying for it; running away from home; driving a car without the owner's permission; stealing something worth more than 
Citation: Wiersma-Mosley JD, Fischer JL, Smith B (2016) Why Do Individuals Select into Congruent vs. Discrepant Drinking Partnerships? Gavin J Addict Res Ther 2016: 1-10.

\$50; going into a house or building to steal something; selling marijuana or other drugs; stealing something worth less than $\$ 50$; and being loud, rowdy, or unruly in a public place. Responses ranged from $0=$ never to $3=5$ or more times. For young adult couple members (Wave III), 8 items included deliberately damaging property that didn't belong to them; stealing something worth more than $\$ 50$; going into a house or building to steal something; selling marijuana or drugs; stealing something worth less than $\$ 50$; buying, selling, or holding stolen property; using someone else's credit card, bank card, or automatic teller card without their permission or knowledge; and writing a bad check. Responses ranged from $0=$ never to $3=5$ or more times.

Adolescent Drinking was self-reported during the adolescent years (Waves I and II). Frequency of alcohol consumption was measured by: "During the past 12 months, on how many days did you drink alcohol?" Quantity of alcohol consumption was measured by: "Think of all the times you have had a drink during the past 12 months. How many drinks did you usually have each time?" A "drink" was defined as a glass of wine, a can of beer, a wine cooler, a shot glass of hard liquor, or a mixed drink. Frequency accounts for times individuals drink, whereas quantity establishes whether participants are drinking heavy or light. Items were multiplied to assess average monthly volume of alcohol consumption during the adolescent years.

Depression was assessed at all three waves resulting in adolescent (averaged across Waves I and II) and young adult (Wave III) depression. Participants responded to 12 items, such as "In the past 12 months, how often have you laughed a lot" and "...how often have you cried a lot." Responses ranged from $0=$ never to $3=$ most or all of the time.

Self-esteem was assessed at all three waves resulting in adolescent (averaged across Waves I and II) and young adult (Wave III) self-esteem, with 4 items including "Do you agree or disagree that you have many good qualities" and "Do you agree or disagree that you have a lot to be proud of?" Response scale ranged from $1=$ strongly disagree to $5=$ strongly agree .

Sensation seeking was assessed during Wave III only. This measure contained 7 paired-choice items, for each of which participants chose the sentence they felt best represented them. Examples included: "I like wild, uninhibited parties" or "I like quiet parties with good conversation"; "I am not interested in experience for its own sake" or "I like to have new and exciting experiences and sensations, even if they are a little frightening, unconventional, or illegal". Each item was dichotomized as $0=$ nonseeking and $1=$ seeking, and averaged.

\section{Interpersonal factors}

Parental alcohol use was assessed by two items reported by the participants' primary parent during adolescence (Wave I): "How often do you [the parent] drink alcohol?" and "How often in the last month have you [the parent] had 5 or more drinks on one occasion?" Responses for both items ranged from
$1=$ never, $2=$ once, $3=$ twice, $4=$ three times, $5=$ four times, and $6=$ five or more times. The two items were averaged.

Peer alcohol use was assessed across the adolescent years (Waves I and II averaged) and young adulthood (Wave III) by asking participants to answer the following question: "Of your 3 best friends, how many drink alcohol at least once a month?". Responses ranged from $0=$ none of my friends, $1=$ one friend, $2=$ two friends, and 3 = three friends.

Outcome variable: Drinking partnerships. To identify Wave III drinking partnerships (and consequently congruency vs. discrepancy), frequency, quantity of alcohol consumption, binge drinking ( $4 / 5$ more drinks for women/men), and getting drunk were assessed (similar to previous research $[2,4]$ ).

Frequency of alcohol consumption was estimated by both partners answering: "During the past 12 months, on how many days did you drink alcohol?" Binge drinking was estimated by both partners answering: "During the past 12 months, on how many days did you drink 4/5 drinks?” Getting drunk was assessed by: "During the past 12 months, on how many days did you get drunk?" Response scale for these 3 questions ranged from $1=1$ or 2 days in the past 12 months to $6=$ every day or almost every day. Quantity of alcohol consumption was assessed by asking both partners: "Think of all the times you have had a drink during the past 12 months. How many drinks did you usually have each time?" A "drink" was defined as a glass of wine, a can of beer, a wine cooler, a shot glass of hard liquor, or a mixed drink. Responses ranged from 1 - 18 drinks.

The current drinking partnership measure creates comparability with the existing drinking partnership literature [5], as well as paralleling the number of clusters found for drinking partnerships using the same Add Health couple dataset [4,7]. A $k$-means iterative cluster analysis determined clusters. This study used cluster analysis of the 8 drinking variables for couples: women's typical quantity of alcohol consumed, frequency, binge drinking, and getting drunk; and men's typical quantity of alcohol consumed, frequency, binge drinking and getting drunk. Paralleling the number of clusters found for drinking partnerships using the Add Health [4,7], the number of clusters was set to four: (1) "Congruent Light and Infrequent" (n = 1075), (2) "Discrepant Male Heavy and Frequent" ( $=181)$, (3) "Discrepant Female Heavy and Frequent" ( $\mathrm{n}=64)$, and (4) "Congruent Heavy Drinkers" ( $n=113)$. Clusters 1 and 4 were grouped together, whereas the discrepant group included Clusters 2 and 3, resulting in $1188(82 \%)$ congruent couples and 245 discrepant heavy/frequent couples (18\%).

\section{Results}

The current study hypothesized that individuals who selected into discrepant drinking partnerships would report more intra- and interpersonal problems. We tested this by examining risk behaviors in (1) adolescent years (individual 
Citation: Wiersma-Mosley JD, Fischer JL, Smith B (2016) Why Do Individuals Select into Congruent vs. Discrepant Drinking Partnerships? Gavin J Addict Res Ther 2016: 1-10

\begin{tabular}{|c|c|c|c|c|c|c|}
\hline \multirow[b]{2}{*}{ Variable } & \multicolumn{3}{|c|}{ Wave I/II Individuals } & \multicolumn{3}{|c|}{ Wave III Paired Couples } \\
\hline & $\begin{array}{l}\text { Adolescent Women } \\
\qquad(\mathrm{n}=750)\end{array}$ & $\begin{array}{l}\text { Adolescent Men } \\
\quad(n=683)\end{array}$ & alpha & $\begin{array}{l}\text { Young Adult Women } \\
\qquad(\mathrm{n}=1433)\end{array}$ & $\begin{array}{l}\text { Young Adult Men } \\
\quad(n=1433)\end{array}$ & alpha \\
\hline Mean Age & $15.41(1.71)$ & $15.87(1.58)$ & & $21.70(2.11)$ & $23.03(2.45)$ & \\
\hline$\%$ nonwhite & $43 \%$ & $42 \%$ & & $34 \%$ & $36 \%$ & \\
\hline Highest Education & na & na & & $12.97(1.95)$ & $12.73(1.97)$ & \\
\hline In School (\% yes) & na & na & & $34 \%$ & $24 \%$ & \\
\hline Delinquency & $.24(.26)$ & $.34(.38)$ & $.82, .89$ & $.03(.12)$ & $.09(.21)$ & $.73, .74$ \\
\hline Adolescent Drinking & $.62(.83)$ & $.92(1.12)$ & & na & na & \\
\hline Depression & $.64(.39)$ & $.57(.33)$ & $.87, .87$ & $.63(.44)$ & $.47(.37)$ & $.83, .83$ \\
\hline Self-esteem & $4.04(.57)$ & $4.20(.51)$ & $.85, .87$ & $3.20(.57)$ & $3.29(.55)$ & $.79, .78$ \\
\hline Sensation Seeking & na & na & & $.32(.26)$ & $.45(.28)$ & $.65, .66$ \\
\hline Parental Drinking & $1.58(.80)$ & $1.61(.91)$ & & na & na & \\
\hline \# of Peer Drinkers & $1.09(1.01)$ & $1.31(1.10)$ & & $.50(.90)$ & $.96(1.17)$ & \\
\hline
\end{tabular}

Table 1: Means and Standard Deviations of Study Demographics and Measures

Note: na $=$ not applicable

report), (2) within young adulthood relationships (paired partner reports), and (3) within overall couple differences (from paired partners' reports) across congruent and discrepant drinking partnerships.

\section{Adolescent risk factors}

Starting with adolescent correlates, a multivariate analysis of variance indicated overall significant differences across Congruent vs. Discrepant groups (Wilks' Lambda $=.96$, $\mathrm{p}<.001$ ); univariate $\mathrm{F}$ tests were calculated (Table 2 for all adolescent risk factor findings). Analyses revealed that there was a significant group main effect indicating that adolescents reported lower delinquency, alcohol use, parental and peer drinking within the congruent group compared to the discrepant group; but no other comparisons were found.

Next, gender as a main effect and interaction were included in the analysis: A multivariate analysis of variance indicated an overall significant effect for gender (Wilks' Lambda $=.93, \mathrm{p}<.001)$ revealing that adolescent men reported higher delinquency, self-esteem, alcohol use, and peer drinking compared to women. A multivariate analysis of variance indicated an overall significant gender by group effect for adolescent risk factors (Wilks' Lambda $=.99, \mathrm{p}<.01$ ), and significant $F$ tests of group by gender interactions for adolescent delinquency and alcohol use. Follow up analyses revealed that men in the congruent drinking partnerships reported lower delinquency and alcohol use in adolescence compared to men within the discrepant group. As for women, those in the congruent drinking partnerships reported less alcohol use than women in the discrepant group; however there were no other comparisons found.

\section{Young adult couple risk factors}

A multivariate analysis of variance indicated overall significant differences across Congruent vs. Discrepant groups for young adult risk factors (Wilks' Lambda $=.86, \mathrm{p}<.001$ ) follow-up univariate $\mathrm{F}$ tests were calculated (refer to table 3 for all young adult risk factor findings). Overall, there was a main effect for young adult delinquency, self-esteem, sensation seeking and peer drinkers, indicating that couples in the congruent drinking partnership reported lower delinquency, sensation seeking, peer drinkers and higher self-esteem as compared to those couples in the discrepant group during young adulthood.

Next, analyses examined gender as main effects and interactions. First, a multivariate analysis of variance indicated an overall significant gender effect (Wilks' Lambda $=.74, \mathrm{p}<.001$ ), whereby men reported higher young adult delinquency, self-esteem, sensation seeking, peer drinking, and lower depression as compared to women. A multivariate analysis of variance indicated an overall between (Congruent vs. Discrepant groups) and within (gender) significant effect for young adult risk factors (Wilks' Lambda $=.97, \mathrm{p}<.01$ ) Follow up analyses revealed a significant effect for young adult delinquency, sensation seeking and peer drinkers. As seen in table 3, men and women reported higher rates of young adult delinquency, sensation seeking, and peer drinking within the discrepant group as compared to the congruent group. And these effects seemed to be much higher for men, as compared to women, in terms of delinquency (.20 vs. .08), sensation seeking (.61 vs. .43), and peer drinkers (1.58 vs. .80). No other gender interactions were found.

\section{Young adult couple differences}

Lastly, in order to examine how similar couples were initially in terms of sociodemographic characteristics, couple differences in means of age, ethnicity, education, and whether they were currently in school were analyzed. One of the more common and useful ways to measure couple similarity is to compute an absolute difference score between two partners [79]. Such difference scores were computed to examine within-couple disparity that may account for selection into the drinking partnerships. 
Citation: Wiersma-Mosley JD, Fischer JL, Smith B (2016) Why Do Individuals Select into Congruent vs. Discrepant Drinking Partnerships? Gavin J Addict Res Ther 2016: 1-10.

\begin{tabular}{|c|c|c|c|}
\hline Variable & $\begin{array}{l}\text { Congruent } \\
(n=1188)\end{array}$ & $\begin{array}{c}\text { Discrepant } \\
(n=245)\end{array}$ & $\mathrm{F}$ \\
\hline \multicolumn{4}{|c|}{ Delinquency } \\
\hline Overall & $.27(.01)$ & $.40(.02)$ & $30.68^{* * *}$ \\
\hline Males & $.30(.01) 1$ & $.53(.03) 6$ & $32.83^{\star \star \star}$ \\
\hline Females & $.23(.01) 1$ & $.28(.03) 6$ & 3.19 \\
\hline \multicolumn{4}{|l|}{ Drinking } \\
\hline Overall & $.68(.03)$ & $1.09(.07)$ & $31.18^{* \star *}$ \\
\hline Males & $.81(.04) 2$ & $1.53(.10) 7$ & $27.20^{\star \star \star}$ \\
\hline Females & $.56(.04) 2$ & $.77(.09) 7$ & $6.77^{\star *}$ \\
\hline \multicolumn{4}{|c|}{ Depression } \\
\hline Overall & $.60(.01)$ & $.59(.03)$ & .26 \\
\hline Males & $.56(.02) 3$ & $.60(.03)$ & 1.06 \\
\hline Females & $.65(.02) 3$ & . $58(.03)$ & 2.34 \\
\hline \multicolumn{4}{|c|}{ Self-esteem } \\
\hline Overall & $4.14(.02)$ & $4.10(.04)$ & .96 \\
\hline Males & $4.23(.02) 4$ & $4.15(.05)$ & 2.12 \\
\hline Females & $4.06(.02) 4$ & $4.06(.05)$ & .003 \\
\hline \multicolumn{4}{|c|}{ Parental Drinking } \\
\hline Overall & $1.57(.03)$ & $1.72(.06)$ & $5.64^{*}$ \\
\hline Males & $1.58(.89)$ & $1.73(.91)$ & 2.04 \\
\hline Females & $1.55(.80)$ & $1.77(.78)$ & $3.87^{\star \star}$ \\
\hline \multicolumn{4}{|c|}{ Peer Drinkers } \\
\hline Overall & $1.10(.03)$ & $1.52(.07)$ & $28.34^{\star \star \star}$ \\
\hline Males & $1.21(.05) 5$ & $1.76(.10) 8$ & $22.41^{\star \star \star}$ \\
\hline Females & $1.00(.05) 5$ & $1.30(1.00) 8$ & $8.13^{\star \star}$ \\
\hline
\end{tabular}

Table 2: Young Adult Congruent vs. Discrepant Drinking Partnerships (Wave III) as a Function of Adolescent Risk Factors (Waves I/II).

Note: Matching numbers indicate significant gender differences; $p<.05$; Standard deviations are in brackets;

${ }^{*} p<.05 ;{ }^{* *} p<.01 ;{ }^{* * *} p<.001$

Difference scores on ethnicity were based on whether or not the couple was of the same ethnicity (e.g., a White/Caucasian man and African American woman would be coded as 1; both partners White/Caucasian would be coded as 0 ). In general, men and women were similar in ethnicity, education, and school enrollment. Thus, couples were paired with partners who were similar in background characteristics, and within both congruent and discrepant drinking partnerships (Table 3).

Analyses tested whether absolute differences in couple risky behaviors were related to congruency vs. discrepancy by first examining a multivariate analysis of variance which indicated an overall significant difference (Wilks' Lambda $=.93, \mathrm{p}<.001$ ); follow-up univariate $\mathrm{F}$ tests were calculated (Table 3). There were significant effects for differences in young adult delinquency, sensation seeking, and peer drinkers. Results revealed that more differences in couple members' reports on young adult delinquency, sensation seeking, and peer drinking were associated with a higher likelihood of selecting into the discrepant drinking partnership compared to the congruent group.

\begin{tabular}{|c|c|c|c|}
\hline Variable & $\begin{array}{l}\text { Congruent } \\
(n=1188)\end{array}$ & $\begin{array}{c}\text { Discrepant } \\
(n=245)\end{array}$ & $\mathrm{F}$ \\
\hline \multicolumn{4}{|c|}{ Young Adult Risk Factors } \\
\hline Male Delinquency & $.07(.01)^{1}$ & $.20(.01)^{6}$ & $73.32^{* * *}$ \\
\hline Female Delinquency & $.02(.04)^{1}$ & $.08(.01)^{6}$ & $34.95^{* * *}$ \\
\hline Male Depression & $.47(.01)^{2}$ & $.49(.03)^{7}$ & .63 \\
\hline Female Depression & $.61(.01)^{2}$ & $.65(.03)^{7}$ & 1.43 \\
\hline Male Self-esteem & $3.30(.02)^{3}$ & $3.22(.04)$ & $5.01^{*}$ \\
\hline Female Self-esteem & $3.22(.02)^{3}$ & $3.14(.04)$ & $4.02^{*}$ \\
\hline Male Sensation Seeking & $.41(.01)^{4}$ & $.61(.02)^{8}$ & $95.02^{* * *}$ \\
\hline Female Sensation Seeking & $.29(.01)^{4}$ & $.43(.02)^{8}$ & $51.3^{* * *}$ \\
\hline Male Peer Drinkers & $.84(.04)^{5}$ & $1.58(.08)^{9}$ & $76.62^{\star * *}$ \\
\hline Female Peer Drinkers & $.42(.03)^{5}$ & $.80(.06)^{9}$ & $34.52^{* * *}$ \\
\hline \multicolumn{4}{|c|}{ Differences in Couples } \\
\hline Age & $.79(.01)$ & $.84(.03)$ & 2.65 \\
\hline Ethnicity & $.30(.01)$ & $.26(.03)$ & .54 \\
\hline Education & $.64(.02)$ & $.66(.03)$ & .51 \\
\hline In school & $.25(.01)$ & $.29(.03)$ & 2.12 \\
\hline Delinquency & $.30(.02)$ & $.56(.03)$ & $55.40^{* * *}$ \\
\hline Depression & $.91(.01)$ & $.92(.02)$ & .46 \\
\hline Esteem & $.80(.01)$ & $.82(.03)$ & .37 \\
\hline Sensation Seeking & $.84(.01)$ & $.89(.03)$ & $3.63^{*}$ \\
\hline Peer Drinkers & $.48(.02)$ & $.71(.03)$ & $36.14^{\star * *}$ \\
\hline
\end{tabular}

Table 3: Young Adult Congruent vs. Discrepant Drinking Partnerships as a Function of Young Adult Risk Factors and Couple Differences (Wave III).

Note: Matching numbers indicate significant gender differences; $p<.05$; Standard deviations are in brackets; ${ }^{*} p<.05 ;{ }^{* *} p<.01$; ${ }^{* *} p<.001$

\section{Discussion}

The current study expands on the drinking partnership literature by assessing the factors associated with selecting into a congruent vs. discrepant drinking partnership. The current study utilizes a longitudinal approach to assess the various adolescent and young adult factors and couple differences that may be related to drinking partnership selection in young adulthood. Overall, the findings demonstrate that there are multiple reasons why individuals select into congruent and discrepant young adult drinking partnerships. It should be noted that the majority of couples (82\%) were drinking congruently, indicating that the selection of romantic partners is primarily related to similarity beyond demographic characteristics. Based on selection, most couples were characterized as "birds of a feather flock together" even in regards to alcohol use within their romantic relationship. Interestingly, couples were similar to each other on demographic variables, such as age, ethnicity, highest education, and enrollment in school; these were similar even within the discrepant drinking couples. The focus of this study was on drinking discrepancy, and results indicated that some individuals select into discrepant drinking partnerships (18\%) for many reasons.

The results indicated that higher levels of adolescent delinquency, alcohol use, parental and peer alcohol use were indicators of selecting into discrepant partnerships. Men reported higher delinquency, self-esteem, alcohol use and peer drinking compared to women during adolescence, which was not surprising. Men with 
Citation: Wiersma-Mosley JD, Fischer JL, Smith B (2016) Why Do Individuals Select into Congruent vs. Discrepant Drinking Partnerships? Gavin J Addict Res Ther 2016: 1-10

lower delinquency and alcohol use during adolescence were more likely to select into the congruent drinking partnership. The discrepant drinking partnerships reported the highest levels of peer drinkers among men, indicating the significance of peer drinking in men's lives. A different pattern emerged for women: lower parental drinking was associated with selecting into the congruent group vs. the discrepant group. Thus, high parental drinking may be a pattern that reflects why women choose men who drink differently. Exploring whether they are selecting men who drink higher or lower than themselves would be the next step in understanding this process.

When examining young adult risk factors, couples in the congruent group reported lower young adult delinquency, sensation seeking, number of peer drinkers, and higher self-esteem compared to the discrepant couples. The risky behaviors, such as delinquency, peer drinking, and higher levels of sensation seeking, were higher in men compared to women, but men also reported higher levels of self-esteem and lower reports of depression, which is not surprising as women typically suffer more so in terms of depression and alcohol $[38,39]$. It was also evident that gender played an important role in the selection of certain partnerships for young adults. For example, the pattern of high risky behaviors was evident for men in the discrepant group. They reported much higher rates of delinquency (.20 vs. .08), sensation seeking (.61 vs. .43), and number of peer drinkers (1.58 vs. .80) compared to women. Perhaps men chose dissimilar partners because they did not think they could do better. As for women, lower young adult delinquency, sensation seeking and number of peer drinkers were related to congruency in partner selection. Thus, young adult men and women were behaving similarly within the congruent drinking partnerships, or at the very least, indicating similar risky behaviors.

Another pattern that emerged was differences within couple behaviors, not just individual factors. For example, when paired couple members differed (whereby one person reported higher/lower than the other) in their reported delinquency, sensation seeking, and peer alcohol use, they had a higher likelihood of selecting into the discrepant drinking partnerships. Thus, those couples who were similar in other behaviors, beyond just drinking, were selecting into congruent drinking partnerships. However, based on this study, Congruent Light and Infrequent drinking (Cluster 1) was combined with the Congruent Heavy drinkers (Cluster 4). Research has indicated numerous issues that arise for those drinking congruently and heavy (i.e., Cluster 4; [4,7]. However, based on just the "congruent" and "discrepant" categorization, it seems drinking discrepantly, regardless of how much alcohol is consumed, derives from various adolescent and young adult risk factors.

The current study highlighted certain risk factors that may explain why individuals select non-similar drinking relationship partners. Based on the literature, it does not seem surprising that those individuals, who are already risky in their behaviors, such as adolescent delinquency, drinking during adolescence, and befriending high drinking peers, are selecting into risky discrepant drinking partnerships. Thus, a pattern seems to be emerging for certain individuals and their choices in risky behaviors.

\section{Strengths and weaknesses}

This study had several advantages over past research. First, the current study explored data from both couple members using a nationally-representative US sample. The longitudinal and nationally representative sample allowed for generalizability of the findings. The Add Health followed the same individuals from adolescence into young adulthood, however couples were only assessed during young adulthood. One major study weakness is measurement, in which Add Health can be somewhat limited with fewer items to fully measure concepts. For example, there are other factors that may be related to selecting into discrepant drinking partnerships (i.e., genetics, motives, and alcohol expectancies) that are not included in the Add Health dataset. Also, with any type of self-report data, there may be issues with social desirability and memory distortions, although this has been found to be rare [80]. Lastly, the current study neglected to examine other factors that are associated with selection into drinking partnerships, such as social environment and sociocultural norms that are predictive of young adult drinking patterns [81], thus additional social determinants including empathy, school connectedness, and self-control should be considered in future research on drinking partnerships.

In conclusion, the current study sheds more light on the drinking partnerships literature as well as the selection of similar and dissimilar romantic partners. Clearly there is ample support for partner similarity in congruent drinking partnerships. However, there are multiple risk factors that may explain why individuals select into the discrepant drinking partnerships. While there are fewer of these couples, they represent an extremely interesting risky group in terms of alcohol-related behaviors. Given these problems, the current research can inform future prevention designs to reduce problems for individuals and their romantic relationships by identifying risk factors for discrepant drinking partnerships, such as delinquency and high sensation seeking. Studying romantic relationships serves as one important context for understanding a variety of behaviors, such as alcohol use, and therefore has implications for broad aspects of young adult and relationship development.

\section{References}

1. Sieving R, Perry C, Williams C (2000) Do friendships change behaviors, or do behaviors change friendships? Examining paths of influence in young adolescents' alcohol use. J Adolesc Health 26: 27-35.

2. Wiersma JD, Fischer JL, Cleveland HH, Reifman A, Harris K (2011) Selection and socialization of drinking among young adult dating, cohabiting, and married partners. Journal of Social and Personal Relationships 28: 182-200.

3. Aron A, Steele JL, Kashdan TB, Perez M (2006) When similar do not attract: Tests of a prediction from the self-expansion model. Personal Relationships 13: 387-396.

4. Wiersma JD, Fischer JL (2014) Young adult drinking partnerships: Alcohol-related consequences and relationship problems six years later. Journal of Studies on Alcohol \& Drugs 75: 704-712.

5. Roberts LJ, Leonard KE (1998) An empirical typology of drinking partnerships and their relationship to marital functioning and drinking consequences. Journal of Marriage and the Family 60: 515-526.

6. Wiersma JD, Fischer JL, Fitzpatrick J (2009) The role of undergraduate romantic partners' drinking in relationship quality and alcohol-related problems. In: DiGuarde KI (ed.). Binge Drinking Research Progress. Nova Science New York, USA. Pg: 39-61. 
Citation: Wiersma-Mosley JD, Fischer JL, Smith B (2016) Why Do Individuals Select into Congruent vs. Discrepant Drinking Partnerships? Gavin J Addict Res Ther 2016: 1-10.

7. Wiersma JD, Cleveland HH, Herrera V, Fischer JL (2010) Intimate partner violence in young adult dating, cohabitating, and married drinking partnerships. Journal of Marriage \& Family 72: 360-374

8. Wechsler H, Austin SB (1998) Binge drinking: The five/four measure. J Stud Alcohol 59: 122-124.

9. Wechsler H, Isaac N (1992) 'Binge' drinkers at Massachusetts colleges: Prevalence, drinking style, time trends, and associated problems. JAMA 267: 2929-2931.

10. Wechsler H, Lee JE, Kuo M, Lee $H$ (2000) College binge drinking in the 1990's: A continuing problem; Results of the Harvard School of Public Health 1999 College Alcohol Study. J Am Coll Health 48: 199-210.

11. Fischer JL, Fitzpatrick J, Cleveland $\mathrm{HH}$ (2007) Linking family functioning to dating relationship quality via novelty-seeking and harm-avoidance personality pathways. Journal of Social and Personal Relationships 24: 575-590.

12. Fischer JL, Wiersma JD (2012) Romantic relationships and alcohol use. Current Drug Abuse Review 5: 98-116.

13. Homish GG, Leonard KE (2007) The drinking partnership and marital satisfaction: The longitudinal influence of discrepant drinking behavior. J Consult Clin Psychol 75: 43-51.

14. Mudar P, Leonard KE, Soltysinski K (2001) Discrepant substance use and marital functioning in newlywed couples. J Consult Clin Psychol 69: 130-134.

15. Ostermann J, Sloan FA, Taylor DH (2005) Heavy alcohol use and marital dissolution in the USA. Soc Sci Med 61: 2304-2316.

16. Leadley K, Clark CL, Caetano R (2000) Couples' drinking patterns, intimate partner violence, and alcohol-related partnership problems. J Subst Abuse 11: $253-263$

17. Ennett ST, Bauman KE (1994) The contribution of influence and selection to adolescent peer group homogeneity: The case of adolescent cigarette smoking. J Pers Soc Psychol 67: 653-663.

18. Kandel DB (1978) Homophily, selection, and socialization in adolescent friendships. American Journal of Sociology 84: 427-436.

19. Pascarella E, Terenzini P (1991) How College Affects Students: Findings and Insights from Twenty Years of Research. Wiley Jossey-Bass, San Francisco, USA

20. Lazarsfeld P, Merton RK (1954) Friendship as a social process: A Substantive and methodological analysis. In: Berger M, Abel T, Page $\mathrm{CH}$ (eds.). Freedom and Control in Modern Society 18: 18-66.

21. Emirbayer M, Goodwin J (1994) Network analysis, culture, and the problem of agency. American Journal of Sociology 99: 1411-1454

22. Acitelli LK, Kenny DA, Weiner D (2001) The importance of similarity and understanding of partners' marital ideals to relationship satisfaction. Personal Relationships 8: 167-185.

23. Buss DM (1994) The evolution of desire: Strategies of human mating. Basic Books, New York, US.

24. Houts RM, Robins E, Huston TL (1996) Compatibility and the development of premarital relationships. Journal of Marriage and Family 58: 7-20.

25. Crawford DW, Houts RM, Huston TL, George LJ (2002) Compatibility, leisure and satisfaction in marital relationships. Journal of Marriage and Family 64 : 433-449.

26. Klohnen EC, Luo S (2003) Interpersonal attraction and personality: What is attractive--self similarity, ideal similarity, complementarity or attachment security? J Pers Soc Psychol 85: 709-722.

27. Shiota MN, Levenson RW (2007) Birds of a feather don't always fly farthest: Similarity in big five personality predicts more negative marital satisfaction trajectories in long-term marriages. Psychol Aging 22: 666-675.

28. Wilson AC, Huston TL (2013) Shared reality and grounded feelings during courtship: Do they matter for marital success? Journal of Marriage and Family 75 : 681-696.

29. Byrne D, Lamberth J (1971) Cognitive and reinforcement theories as complementary approaches to the study of attraction. In: Murstein BI (ed.). Theories of attraction and love. Springer, New York, USA. Pg no: 59-84.
30. Aron A, Aron E (1986) Love and the expansion of self: Understanding attraction and satisfaction. Hemisphere Publishing Corporation, New York, USA.

31. Aron A, Aron EN, Norman C (2001) The self expansion model of motivation and cognition in close relationships and beyond. In: Clark M, Fletche $\mathrm{G}$ (eds.). Blackwell handbook in social psychology. Interpersonal processes. Volume 2, Oxford: Wiley-Blackwell, Oxford, UK. Pg no: 478-501.

32. Hawkins JD, Catalano RF, Miller JY (1992) Risk and protective factors for alcohol and other drug problems in adolescence and early adulthood: Implications for substance abuse prevention. Psychol Bull 112: 64-105.

33. Petraitis J, Flay BR, Miller TQ (1995) Reviewing theories of adolescent substance use: Organizing pieces in the puzzle. Psychol Bull 117: 67-86.

34. White HR (1990) The drug use-delinquency connection in adolescence. In: Weisheit R (ed.). Drugs, crime and criminal justice. Anderson Publishing Co. Cincinnati, OH, USA. Pg no: 215-256.

35. Albee GW, Kessler M (1977) Evaluating individual deliverers: Private practice and professional standards review organizations. Professional Psychology 8: $502-515$

36. Sterk CE (1999) Fast Lives: Women Who Use Crack Cocaine. Temple University Press, Philadelphia, PA, USA.

37. Abbey A, Smith MJ, Scott RO (1993) The relationship between reasons for drinking alcohol and alcohol consumption: An interactional approach. Addictive Behaviors 18: 659-670

38. Grant BF, Harford TC (1995) Comorbidity between DSM-IV alcohol use disorders and major depression: Results of a national survey. Drug and Alcoho Depend 39: 197- 206

39. Helzer JE, Pryzbeck TR (1988) The co-occurrence of alcoholism with othe psychiatric disorders in the general population and its impact on treatment. $J$ Stud Alcohol and Drugs 49: 219-224.

40. Wilsnack RW, Klassen AD, Wilsnack SC (1986) Retrospective analysis of lifetime changes in women's drinking behavior. Adv Alcohol Subst Abuse 5 : 9-28.

41. Wilsnack SC, Klassen AD, Schur BE, Wilsnack RW (1991) Predicting onset and chronicity of women's problem drinking: A five-year longitudinal analysis. Am J Public Health 8: 305-318.

42. Cooper ML, Frone MR, Russell M, Mudar P (1995) Drinking to regulate positive and negative emotions: A motivational model of alcohol use. J Pers Soc Psychol 69: 990-1005.

43. Cooper ML, Russell M, Skinner JB, Frone MR, Mudar P (1992) Stress and alcohol use: Moderating effect of gender, coping and alcohol expectancies. $J$ Abnorm Psychol 101: 139-152.

44. Krebs H, Weyers P, Janke W (1998) Validation of the German version of Cloninger's TPQ: Replication and correlations with stress, coping, mood measures, and drug use. Personality and Individual Differences 24: 805-814.

45. Nolen-Hoeksema S, Morrow J (1991) A prospective study of depression and posttraumatic stress symptoms after a natural disaster: The 1989 Loma Prieta earthquake. J Pers Soc Psychol 61: 115-121.

46. Baumeister RF (1991) Escaping the self: Alcoholism, spirituality, masochism, and other flights from the burden of selfhood. Basic Books, New York, USA.

47. Newcomb MD, Maddahian E, Bentler PM (1986) Risk factors for drug use among adolescents: Concurrent and longitudinal analyses. Am J Public Health 76: 525-531.

48. Leary MR, Schreindorfer LS, Haupt AL (1995) The role of low self-esteem in emotional and behavioral problems: why is low self-esteem dysfunctional? J Soc Clin Psychol 14: 297-314.

49. Baumeister RE (1993) Understanding the inner nature of low self- esteem Uncertain, fragile, protective, and conflicted. In: Baumeister R (ed.). Self-esteem: The puzzle of low self-regard. Plenum Press, New York, USA.

50. Bednar RL, Wells MG, Peterson SR (1989) Self-esteem: Paradoxes and innovations in clinical theory and practice. American Psychological Association Washington DC, USA.

51. Mecca AM, Smelser NJ, Vasconcellos J (1989) The social importance of self-esteem. The Regents of the University of California Press, Berkley, USA 
Citation: Wiersma-Mosley JD, Fischer JL, Smith B (2016) Why Do Individuals Select into Congruent vs. Discrepant Drinking Partnerships? Gavin J Addict Res Ther 2016: 1-10

52. Zuckerman M (1979) Sensation seeking: Beyond the optimal level of arousal. Taylor \& Francis Group, Abingdon, UK.

53. Arnett JJ (1998) Learning to Stand Alone: The Contemporary American Transition to Adulthood in Cultural and Historical Context. Human Development 41: $295-315$

54. Magid V, MacLean MG, Colder CA (2007) Differentiating between sensation seeking and impulsivity through their mediated relations with alcohol use and problems. Addict Behav 32: 2046-2061.

55. Zuckerman M (1994) Behavioral expressions and biosocial bases of sensation seeking. Cambridge University Press, New York, USA.

56. Arnett JJ (1994) Are college students adults? Their conceptions of the transition to adulthood. Journal of Adult Development 1: 154-168

57. Pandina RJ, Labouvie EW, White HR (1984) Potential contributions of the life span developmental approach to the study of adolescent alcohol and drug use: The Rutgers Health and Human Development Project, a working model. Journal of Drug Issues 14: 253-268.

58. Bates ME, Labouvie EW, White HR (1986) The effect of sensation seeking needs on changes in drug use during adolescence. Bull Social Psychology of Addictive Behaviors 5: 29-36.

59. Del Boca FK, Darkes J, Greenbaum PE, Goldman MS (2004) Up close and personal: temporal variability in the drinking of individual college students during their first year. J Consult Clin Psychol 72: 155-164.

60. White HR, McMorris BJ, Catalano RF, Fleming CB, Haggerty KP, et al (2006). Increases in alcohol and marijuana use during the transition out of high school into young adulthood: The effects of leaving home, going to college, and high school protective factors. J Stud Alcohol 67: 810-822.

61. Fleming CB, White HR, Catalano RF (2011 Romantic relationships and substance use in early adulthood: An examination of the influences of relationship type, partner substance use, and relationship quality. J Health Soc Behav 51: 153-167.

62. Connors GJ, Sobell MB (1986) Alcohol and drinking environment: Effects on affect and sensations, person perception, and perceived intoxication. Cognitive Therapy and Research 10: 389-402.

63. Lowe G, Foxcroft DR, Sibley D (1993) Adolescent drinking and family life Harwood Academic Publishers, Reading, UK.

64. Barnes GM (1990) Impact of the family on adolescent drinking patterns. In Collins RL, Leonard KE, Searles JS (eds.). Alcohol and the family: Research and clinical perspectives. Guilford Press, New York, USA. Pg no: 137-161.

65. Collins RL, Leonard KE, Searles JS (1990) Alcohol and the family: Research and clinical perspectives. Guilford Press, New York, USA

66. Thompson KM, Wilsnack RW (1987) Parental influence on adolescent drinking: Modeling, attitudes, or conflict? Youth and Society 19: 22-43.

67. Graham JW, Marks G, Hansen WB (1991) Social influence processes affecting adolescent substance use. J Appl Psychol 76: 291-298.
68. Fromme K, Ruela A (1994) Mediators and moderators of young adults' drink ing. Addiction 89: 63-71.

69. Reifman A, Barnes GM, Dintcheff A, Farrell MP, Utheg L (1998) Parental and peer influences on the onset of heavier drinking among adolescents. J Stud Alcohol 59: 311-317.

70. Cleveland HH, Wiebe RP (2003) The moderation of adolescent-to-peer similarity in tobacco and alcohol use by school levels of substance use. Child Development 74: 279-291.

71. Gilligan C (1982) In a different voice: Psychological theory and women's development. Harvard University Press, Cambridge, MA, USA

72. Moffitt TE, Caspi A, Rutter M, Silva PA (2001) Sex, antisocial behavior, and mating: Mate selection and early childbearing. In: Sex Differences in Antisocial Behaviour: Conduct Disorder, Delinquency, and Violence in the Dunedin Longitudinal Study. Cambridge University Press, Cambridge, United King dom. Pg no: 184-197.

73. Covington SS, Surrey JL (1997) The relational model of women's psychological development: Implications for substance abuse. In: Wilsnack RW Wilsnack SC (eds.). Gender and alcohol: Individual and social perspectives. Rutgers Center of Alcohol Studies, Piscataway, NJ, USA. Pg no: 335-351.

74. Leonard KE, Mudar PJ (2003) Peer and partner drinking and the transition to marriage: A longitudinal examination of selection and influence processes. Psychol Addict Behav 17: 115-125

75. Hammer T, Vaglum P (1989) The increase in alcohol consumption among women: A phenomenon related to accessibility or stress? A general population study. Br J Addict 84: 767-775.

76. Wilsnack SC, Wilsnack RW, Klassen AD (1984) Drinking and drinking problems among women in a US national survey. Alcohol Health \& Research World 9: 3-13.

77. Cronkite RC, Moos RH (1984) Sex and marital status in relation to the treatment and outcome of alcoholic patients. Sex Roles 11: 93-112.

78. Udry JR (2003) The National Longitudinal Study of Adolescent to Adult Health (Add Health), Waves I \& II, 1994-1996; Wave III, 2001-2002. Carolina Population Center, University of North Carolina, Chapel Hill, NC, USA

79. Luo S, Chen H, Yue G, Zhang G, Zhaoyang R, et al. (2008) Predicting marital satisfaction from self, partner, and couple characteristics: Is it me, you, or us? J Pers 76: 1231-1266.

80. Winters KC, Stinchfield RD, Henly GA, Schwartz RH (1990) Validity of adolescent self-report of alcohol and other drug involvement. Int J Addict 25 $1379-1395$

81. Curcio AL, Mak AS, George AM (2016) Predictors of drinking behavior among adolescents and young adults: A new psychosocial control perspective. International Journal of Child, Youth, and Family Studies 7: 81-103. 